\title{
Simultaneously Improving Mechanical Properties and Stress Corrosion Cracking Resistance of High-Strength Low-Alloy Steel via Finish Rolling within Non-recrystallization Temperature
}

\author{
Hongchi Ma ${ }^{1,2} \cdot$ Baijie Zhao $^{2} \cdot$ Yi Fan $^{2} \cdot \mathrm{Kui}_{\text {Xiao }}{ }^{1,3} \cdot$ Jinbin $\mathrm{Zhao}^{2} \cdot$ Xuequn Cheng $^{1} \cdot$ Xiaogang Li $^{1}$ \\ Received: 12 April 2020 / Revised: 19 July 2020 / Accepted: 9 August 2020 / Published online: 13 November 2020 \\ (c) The Chinese Society for Metals (CSM) and Springer-Verlag GmbH Germany, part of Springer Nature 2020
}

\begin{abstract}
The effect of hot rolling process on microstructure evolution, mechanical properties and stress corrosion cracking (SCC) resistance of high-strength low-alloy (HSLA) steels was investigated by varying the finish rolling temperature (FRT) and total rolling reduction. The results revealed granular bainite with large equiaxed grains was obtained by a total rolling reduction of $60 \%$ with the FRT of $950{ }^{\circ} \mathrm{C}$ (within recrystallization temperature $T_{\mathrm{r}}$ ). The larger grain size and much less grain boundaries should account for the relatively lower strength and SCC resistance. A larger rolling reduction of $80 \%$ under the same FRT resulted in the formation of massive martensite-austenite (M/A) constituents and resultant low ductility and SCC resistance. In contrast, a good combination of strength, ductility and SCC resistance was obtained via $80 \%$ rolling reduction with the FRT of $860^{\circ} \mathrm{C}$ (within non-recrystallization temperature $T_{\mathrm{nr}}$ ), probably because of the fine grain size and M/A constituents, as well as a high density of grain boundary network.
\end{abstract}

Keywords High-strength low-alloy (HSLA) steel $\cdot$ Finish rolling temperature $\cdot$ Non-recrystallization temperature $\cdot$ Stress corrosion cracking $(\mathrm{SCC}) \cdot$ Grain boundary character $\cdot$ Martensite-austenite $(\mathrm{m} / \mathrm{a})$ constituents

\section{Introduction}

High-strength low-alloy (HSLA) steels have been widely used in ocean engineering structures such as vessels, bridges and offshore platforms, because of their excellent mechanical properties, formability and weldability [1,2]. As these structures are usually exposed in corrosive environment for a long time and bear great loading, they are supposed to require a good combination of strength-toughness and

Available online at http://link.springer.com/journal/40195.

Xuequn Cheng

chengxuequn@ustb.edu.cn

1 Key Laboratory for Corrosion and Protection (MOE), Institute for Advanced Materials and Technology, University of Science and Technology Beijing, Beijing 100083, China

2 Jiangsu Key Laboratory for Premium Steel Materials, Nanjing Iron \& Steel United Co., Ltd., Nanjing 210035, China

3 State Key Laboratory of Metal Material for Marine Equipment and Application, Ansteel, Anshan 114021, China corrosion resistance, especially stress corrosion cracking (SCC) resistance [3-6].

Given that HSLA steels are generally produced through microalloying and thermochemical controlled processing $[7,8]$, hot rolling processing parameters, especially finish rolling temperature (FRT) and accumulative rolling reduction, usually have a notable influence on the final microstructure and mechanical properties (strength, ductility, impact toughness, etc.) [9-13]. Generally, the microstructure can be refined with the increase of total rolling reduction and thereby improving the mechanical properties [10-12]. A lot of work has been done with respect to the effect of FRT on microstructure and mechanical properties of HSLA steels [13-22]. The principal conclusion that can be drawn from these studies is that a higher FRT usually results in a recrystallized structure while elongated or acicular ferrite can be obtained at a lower FRT. The grain size can be refined and the mechanical properties may be improved with the decrease in FRT irrespective of within recrystallization temperature $\left(T_{\mathrm{r}}\right)$ or below non-recrystallization temperature $\left(T_{\mathrm{nr}}\right)$. For instance, Chen et al. showed that recrystallized microstructure was obtained with FRT within $T_{\mathrm{r}}$ and the grain size can be refined from 17.3 to $8.5 \mu \mathrm{m}$ by decreasing 
FRT from 1083 to $966{ }^{\circ} \mathrm{C}$ [20]. Saastamoinen et al. [21] revealed that the FRT within $T_{\mathrm{nr}}$ also resulted in fine effective grain size and improved impact toughness for a directquenched steel. Yu et al. [16] revealed that with the decrease in FRT from 115 to $900{ }^{\circ} \mathrm{C}$, the yield strength, total elongation and impact toughness were simultaneously increased. The significant improvement in mechanical properties by lower FRT was attributed to the refined martensite lath with higher density of high-angle grain boundaries. Nevertheless, finish rolling in two-phase regime is generally not advisable except for some special purposes [23]. Warm rolling in this regime not only needs high rolling force, but also may result in abnormally coarse-grained structure and texture inhomogeneity through the thickness direction [18, 24].

However, to the best of our knowledge, little work has been reported about the effect of hot rolling process on corrosion or SCC behavior of HSLA steels [25]. The work of Ohaeri et al. [25] revealed that thermomechanical processing at different conditions could introduce crystallographic texture and resulted in corrosion-resistance variation. Hot rolling at a slightly higher temperature and faster cooling rate produced a higher intensity of corrosion-resistant $<111>|| N D$-oriented grains and thereby better corrosion resistance [25]. Investigation of other materials indicated that the hot or cold rolling processing parameters could improve or deteriorate the corrosion or SCC resistance by changing the grain size, crystallographic texture and grain boundary characteristics, etc. [26-30].

Thus, the key hot rolling parameters, e.g., FRT and rolling reduction may have some influence on the corrosion or SCC resistance of hot-rolled HSLA steels. Inspired by this motivation, this work was dedicated to investigate the effect of FRT and rolling reduction on microstructure evolution, mechanical properties and especially the SCC resistance of HSLA steels.

\section{Experimental}

\subsection{Materials Preparation}

The studied material is a kind of $690 \mathrm{MPa}$ grade HSLA steel with the following chemical compositions (wt\%): $0.11 \mathrm{C}$, $0.20 \mathrm{Si}, 1.05 \mathrm{Mn}, 0.008 \mathrm{P}, 0.002 \mathrm{~S}, 0.46 \mathrm{Cr}, 1.20 \mathrm{Ni}, 0.02$ $\mathrm{Cu}, 0.48 \mathrm{Mo}, 0.06 \mathrm{Nb}, 0.03 \mathrm{~V}, 0.01 \mathrm{Ti}, 0.04 \mathrm{Al}, 0.0018 \mathrm{Ca}$ and $\mathrm{Fe}$ balance. The steel was produced in a vacuum induction furnace and cast into a slab with thickness of $50 \mathrm{~mm}$. Then, three cast slabs were hot rolled with different rolling processes varying in FRT and rolling reduction. One slab was homogenized at $1200^{\circ} \mathrm{C}$ for $1 \mathrm{~h}$, and hot rolled to $20 \mathrm{~mm}$ via three passes with finish rolling temperature (FRT) at $950{ }^{\circ} \mathrm{C}$, then followed by air cooling to room temperature (designated as R1). Another two were also homogenized at $1200{ }^{\circ} \mathrm{C}$ for $1 \mathrm{~h}$, and hot rolled to $10 \mathrm{~mm}$ via six passes with FRT at 950 and $860{ }^{\circ} \mathrm{C}$ (designated as R2 and R3, respectively), and air cooled to room temperature. Note that the $T_{\mathrm{nr}}$ of this steel was estimated to be $\sim 870{ }^{\circ} \mathrm{C}$ according to Boratto equation $[31,32]$. These two FRTs were set to be within $T_{\mathrm{r}}$ and $T_{\mathrm{nr}}$. The rolling schedules of the three steels are shown in Fig. 1.

\subsection{Microstructure Characterization}

The microstructures of three samples were observed with an FEI Quanta 250 scanning electron microscope (SEM) after fine polish with $1.0 \mu \mathrm{m}$ diamond suspension and etching with $4 \%$ nital solution. For substructure observation, the 3-mm-diameter disks were ground to a thickness of $50 \mu \mathrm{m}$ and then twin-jet electropolished at an applied voltage of $20 \mathrm{~V}$, using a solution consisting of $8 \%$ perchloric acid and $92 \%$ ethanol at $-30{ }^{\circ} \mathrm{C}$. Their microstructures were examined by a JEM $2010 \mathrm{~F}$ transmission electron microscope (TEM).

\subsection{EBSD Analysis}

To analyze the effect of grain boundary characteristics on SCC resistance, the grain boundary distribution and features were revealed by electron backscatter diffraction (EBSD). The specimens were ground with 3,000 grit emery papers and mechanically polished with $1.0 \mu \mathrm{m}$ diamond suspension. Then, they were electropolished at $450 \mathrm{~mA} / \mathrm{cm}^{2}$ in the solution composed of $8 \%$ perchloric acid and $92 \%$ ethanol at room temperature for $1 \mathrm{~min}$. Orientation imaging was carried out using an FEI Quanta 650F with the HKL Channel 5 collection system. EBSD mapping was performed using a step size of $0.2 \mu \mathrm{m}$ and an accelerating voltage of $20 \mathrm{kV}$ with a total scanned area of $100 \times 100 \mu \mathrm{m}$.

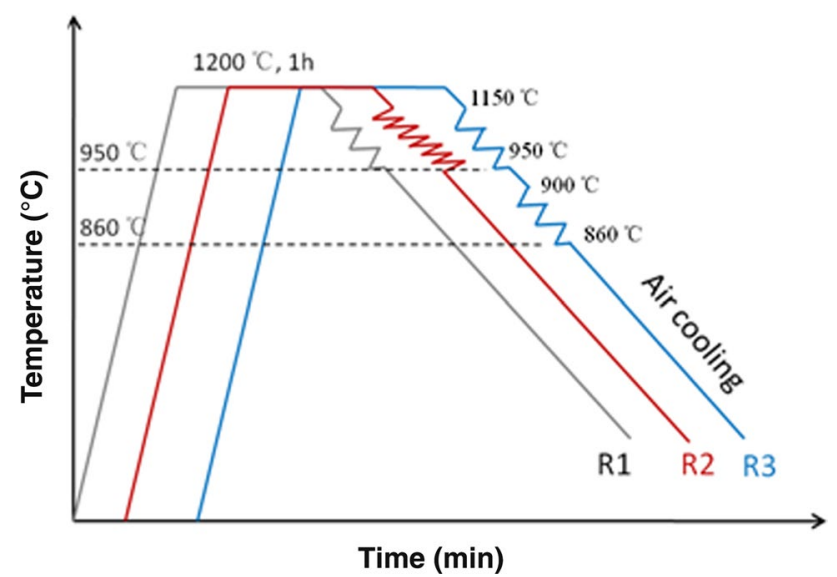

Fig. 1 Hot rolling schedules of three experimental steels 


\subsection{SSRT Tests}

Slow strain rate tensile (SSRT) tests were usually employed to quantitatively evaluate materials' susceptibility to SCC in corrosive environment. The SCC susceptibility or resistance of various samples in this work was comparatively studied by using SSRT method with a strain rate of $10^{-6} / \mathrm{s}$. The tests were conducted according to ASTM G129. Detailed procedure and experimental setup can be found in our previous work [33, 34]. Dog-bone tensile specimens were cut along rolling direction and ground sequentially to $2000 \#$ grit emery papers with the grinding direction parallel to the loading direction. The specimens were then rinsed with deionized water, degreased in dehydrated ethanol by ultrasonic cleaner and sealed with epoxy resin with gauge section of approximately $20 \mathrm{~mm}$. An atomizer was used to pump moisture into the plexiglass to form a thin electrolyte on the specimen surface to simulate marine atmosphere. As previous researches have indicated that HSLA steels were vulnerable to SCC or corrosion fatigue in $\mathrm{SO}_{2}$-polluted marine atmosphere [35-38], a simulated solution of $3.5 \% \mathrm{NaCl}+0.01 \mathrm{~mol} / \mathrm{L} \mathrm{NaHSO}{ }_{3}$ with $\mathrm{pH} \sim 3.8$ was used to provide a severe and acidic marine atmosphere environment that contains $\mathrm{SO}_{2}$. Prior to each $\mathrm{SCC}$ test, the moisture was pumped for $2 \mathrm{~h}$ and continued until fracture of the specimen. After the fracture, the elongation and area reduction of each specimen were calculated after removing the corrosion products. The loss percentage of ductility (elongation and area reduction) was determined to evaluate the SCC susceptibility of each sample:

$I_{\delta}=\left(1-\frac{\delta_{\mathrm{s}}}{\delta_{0}}\right) \times 100$,

$I_{\psi}=\left(1-\frac{\psi_{\mathrm{s}}}{\psi_{0}}\right) \times 100$

where $\delta_{\mathrm{s}}, \delta_{0}$ and $\Psi_{\mathrm{s}}, \Psi_{0}$ are the elongation and area reduction measured in atmosphere and in air, respectively. $I_{\delta}$ and $I_{\Psi}$ represent the loss percentage of elongation and area reduction of fracture in atmosphere compared with that in air. Each sample was reproduced three times to ensure the reliability of the experimental data.

\section{Results and Discussion}

\subsection{Composition and Microstructure Analysis}

\subsubsection{Microstructure Observation}

SEM images of the microstructures are presented in Fig. 2. It shows that the microstructures of three samples are similar. All of them are basically granular bainite consisting of bainitic ferrite matrix and a large amount of M/A constituents. Owing to the considerable content of alloying elements, especially the austenite stabilizer such as $\mathrm{Mn}$ and $\mathrm{Si}$, the pearlite transformation was delayed and the granular bainite was obtained as the final product. Among them, R1 exhibits fully recrystallized grains with equiaxed prior austenite grain boundaries (PAGBs), probably due to recrystallization at high rolling temperature [16]. The microstructure of R2 is composed of ferrite and massive M/A constituents with the original PAGBs not observed, also indicating the occurrence of recrystallization in this rolling condition. The massive $\mathrm{M} / \mathrm{A}$ constituents with typical size of 3-5 $\mu \mathrm{m}$ are retained in the matrix probably due to the large rolling reduction and high rolling temperature. Large rolling reduction could introduce high density of dislocations or dislocation cells with high deformation stored energy which favored the kinetic of phase transformation [23, 39, 40]. Meanwhile, the high rolling temperature was favorable for the long-range diffusion of carbon atoms and thereby carbon partitioning to form carbon-enriched austenite zones, which were subsequently transformed into massive M/A constituents [41, 42]. In contrast, the PAGBs of R3 were retained and apparently elongated with dispersive and fine M/A constituents embedded
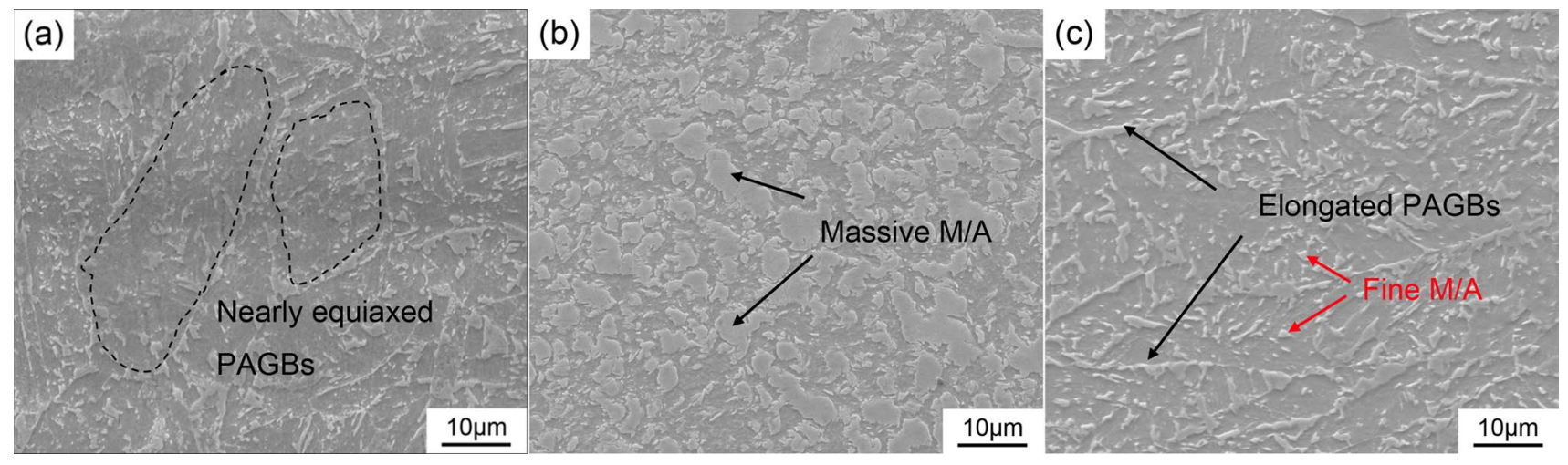

Fig. 2 SEM images of the microstructure of R1 a, R2 b, R3 c 
within the bainitic ferrite matrix, suggesting that the FRT of R3 was well below $T_{\mathrm{nr}}$ [43]. In this case, the prior austenite grains could be severely deformed and crushed during rolling and were thus greatly refined. Then, they would be further refined during the subsequent air cooling because of numerous nuclei for phase transformation and high deformation stored energy [23, 44].

\subsubsection{EPMA Analysis}

To verify the chemical segregation of M/A constituents caused by rolling procedure and phase transformation, the elemental mapping of R3 was measured by an electron probe micro-analyzer (EPMA), shown in Fig. 3. It reveals that carbon is notably segregated in M/A constituents, which is consistent with our assumption and other works [45-47]. However, no apparent segregation of other alloy elements (Ni, Mn, Cr, etc.) was observed although $\mathrm{Mn}$ was reported to segregate at the interface of M/A constituents and matrix [45]. It may be due to the lower diffusivity of these heavy alloy elements or just because of the relatively lower spatial resolution and detection limit of EPMA technique compared to APT.

\subsubsection{TEM Characterization}

Given that the microstructures of three samples are similar, the samples R1 and R3 were selected for TEM observation. Figure 4 shows the TEM bright field images of R1 and R3 with indexed SAED pattern of M/A constituents. The microstructural features of $\mathrm{R} 1$ are mainly retained austenite and dislocation cells, whereas R3 contains retained austenite, dislocation cells and lath martensite with high density of dislocations. The substantially higher density of dislocations of $\mathrm{R} 3$ compared to $\mathrm{R} 1$ is probably due to multipass rolling within $T_{\mathrm{nr}}$.

\subsection{EBSD Analysis}

\subsubsection{Crystallographic Orientation}

Figure 5 shows inverse pole figure (IPF) maps and grain size distribution of three samples measured by EBSD. The colors of various grains correspond to different crystallographic orientation as shown in the stereographic triangle inserted in the right corner of Fig. 5b. The overall crystallographic orientation of these samples is relatively random with no preferred orientation. R1 presents equiaxed grains surrounded by high-angle grain boundaries (HAGBs), indicating the occurrence of full recrystallization during hot rolling above $950{ }^{\circ} \mathrm{C}$. There is little difference in crystallographic orientation feature for samples R2 and R3. Both of them show that large grains mostly contain several substructures with different orientations. Fine subgrains were found to form within larger size of elongated bainitic ferrite. And several lowangle grain boundaries (LAGBs) were introduced within the elongated ferrite grains, indicating that the original austenite grains were segmented by formation of LAGBs through

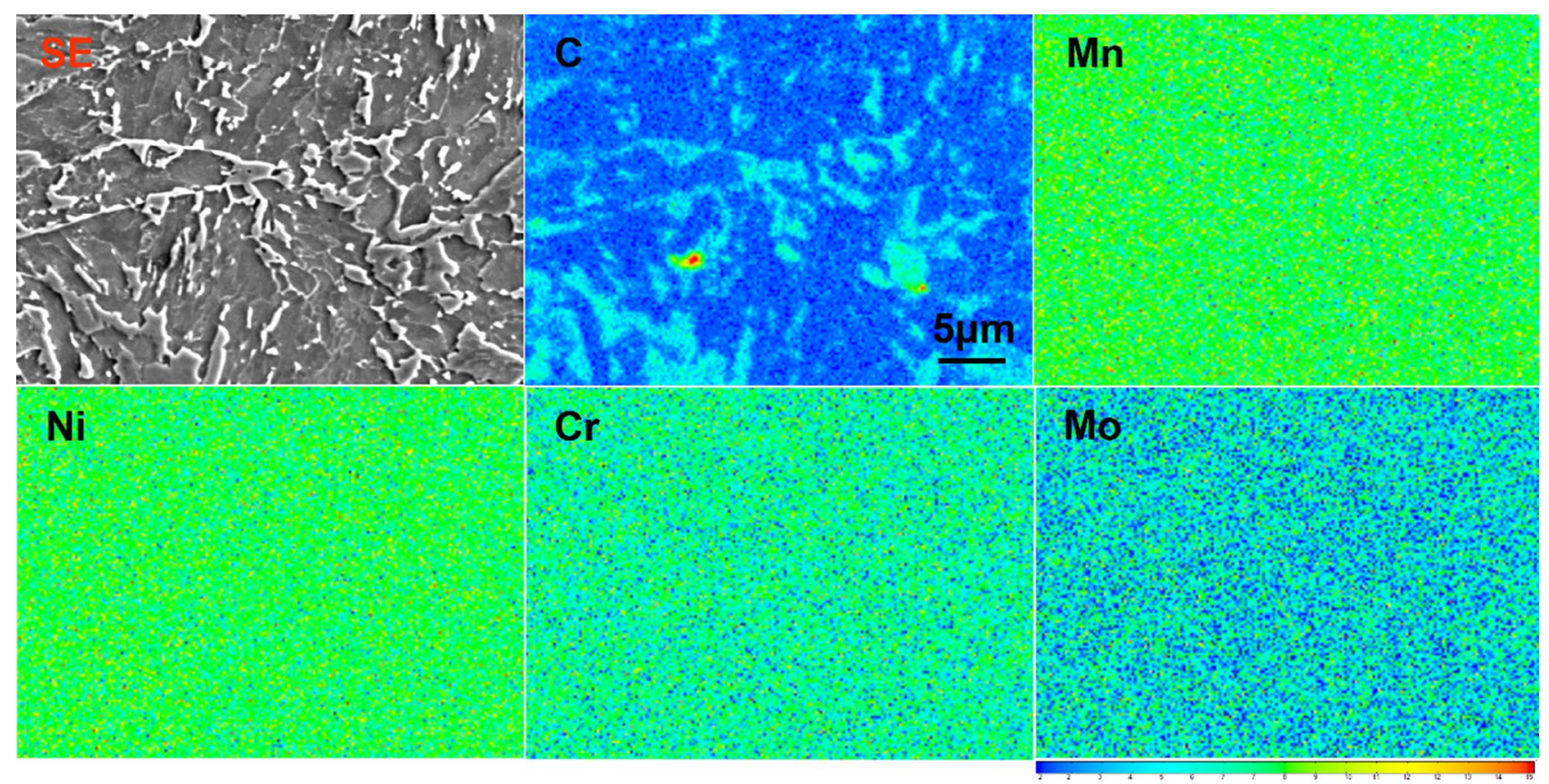

Fig. 3 Elemental mapping of main alloy elements of R3. The color scale indicates increasing concentration from blue to red 

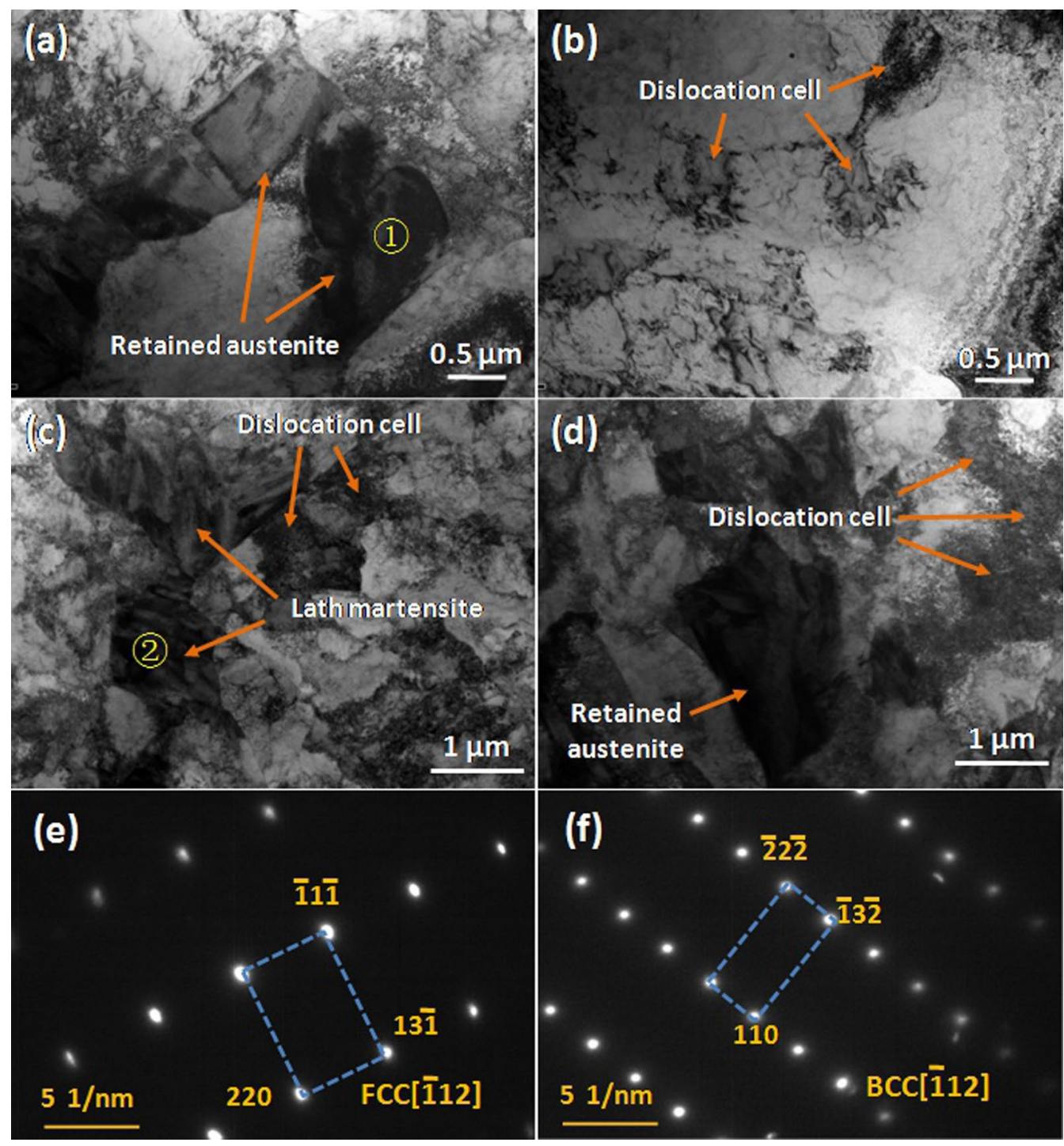

Fig. 4 TEM bright field images of R1 a, b, R3 c, d, SAED pattern of point (1) e, (2) $\mathbf{f}$

dynamic phase transformation. Based on obtained IPF pattern of three samples, the grain size distribution and average grain sizes were calculated and shown in Fig. 5d. Effective grains were mostly smaller than $5 \mu \mathrm{m}$ for all three samples, and the average grain sizes for R1-R3 were calculated to be $4.66,2.67$ and $2.44 \mu \mathrm{m}$, respectively. The grain sizes of R2 and R3 were much finer than that of R1 probably because of more rolling reduction and lower FRT.

\subsubsection{Grain Boundary Distribution}

Based on EBSD measurement, the distribution and density of different grain boundaries for three samples are presented in Fig. 6. The red lines represent LAGBs with the misorientation angle within $2^{\circ}-15^{\circ}$, whereas the black lines correspond to HAGBs with misorientation higher than $15^{\circ}$.
Since coincident site lattice (CSL) boundaries with low $\Sigma(\leq 29)$ are generally considered to be immune to cracking due to lower energy, lower mobility and higher atomic packing [48-51], $\Sigma 3$ grain boundaries were identified and analyzed in this work to correlate their densities with SCC resistance. It should to be noted that other CSL boundaries with $\Sigma>3$ were considered to be much less than $\Sigma 3$ grain boundaries and can be neglected in this study $[11,52]$. The grain boundary distribution maps (Fig. 6a-c) show that HAGBs are predominant for R1. The coarse and polygonal bainitic ferrite is mostly surrounded by HAGBs, and there are very few LAGBs and $\Sigma 3$ boundaries within ferrite grains. By contrast, a remarkably higher density of grain boundaries can be observed in R2 and R3, especially LAGBs and $\Sigma 3$ boundaries. The misorientation angle distribution (Fig. 6d) also reveals there are much more LAGBs within R2 and 

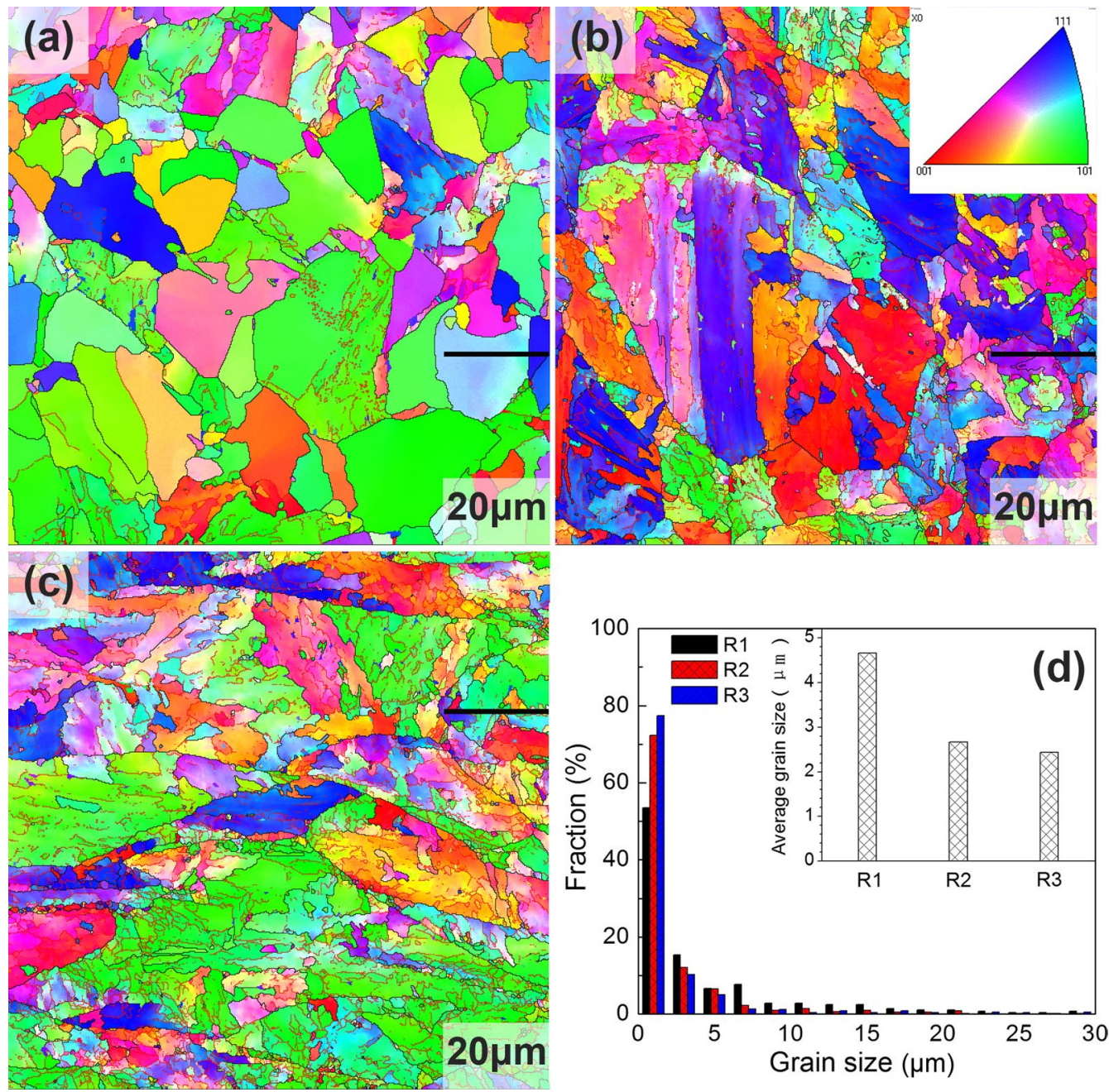

Fig. 5 Inverse pole figure (IPF) maps a-c and average grain size $\mathbf{d}$ of three samples

$\mathrm{R} 3$. This is probably due to more total rolling reduction for them. Schwartz indicated that compression deformation or rolling reduction by $82 \%$ could greatly increase the fraction of $\Sigma 3$ boundaries through multiple twinning [53]. The grain boundary densities (defined as grain boundary length per unit area) of various types were statistically calculated and shown in Fig. 6e, which are in good agreement with Fig. 6a-c. The notably higher grain boundary density of R3 relative to $\mathrm{R} 1$ indicates that multipass rolling within $T_{\mathrm{nr}}$ can greatly refine effective grain size and increase grain boundary density (especially LAGBs and $\Sigma 3$ ), which are supposed to have a beneficial effect on SCC resistance.

\subsubsection{Kernel Average Misorientation (KAM)}

To reveal local strain distribution, the kernel average misorientation (KAM) maps of the three samples were measured and shown in Fig. 7. The KAM values characterize the local misorientation caused by geometrically necessary dislocations, and thus can reveal the dislocation density or local strain level in material $[54,55]$. The KAM map of R1 shows a low level of local strain or dislocation density, which is consistent with TEM image (Fig. 4b). Since R1 was roughly rolled at high temperature, the strain was greatly released due to recovery and recrystallization, accompanied by merging and annihilation of dislocations. By contrast, the KAM values of R2 and R3 are remarkably higher than that of R1, indicating much higher levels of residual strain within grains. In addition, it should be noted that the relatively higher value of KAM coincides well with LAGB areas by comparing Fig. 6a with Fig. 7a. This finding implies that the cumulative plastic deformation during hot rolling process is favorable for the formation of LAGBs in subsequent phase transformation. It was suggested that the severely deformed grains and high density of dislocations could be transformed into several subgrains or dislocation cells, thereby greatly refining grain size and introducing large number of LAGBs [56]. Therefore, the high density of HAGBs and LAGBs 


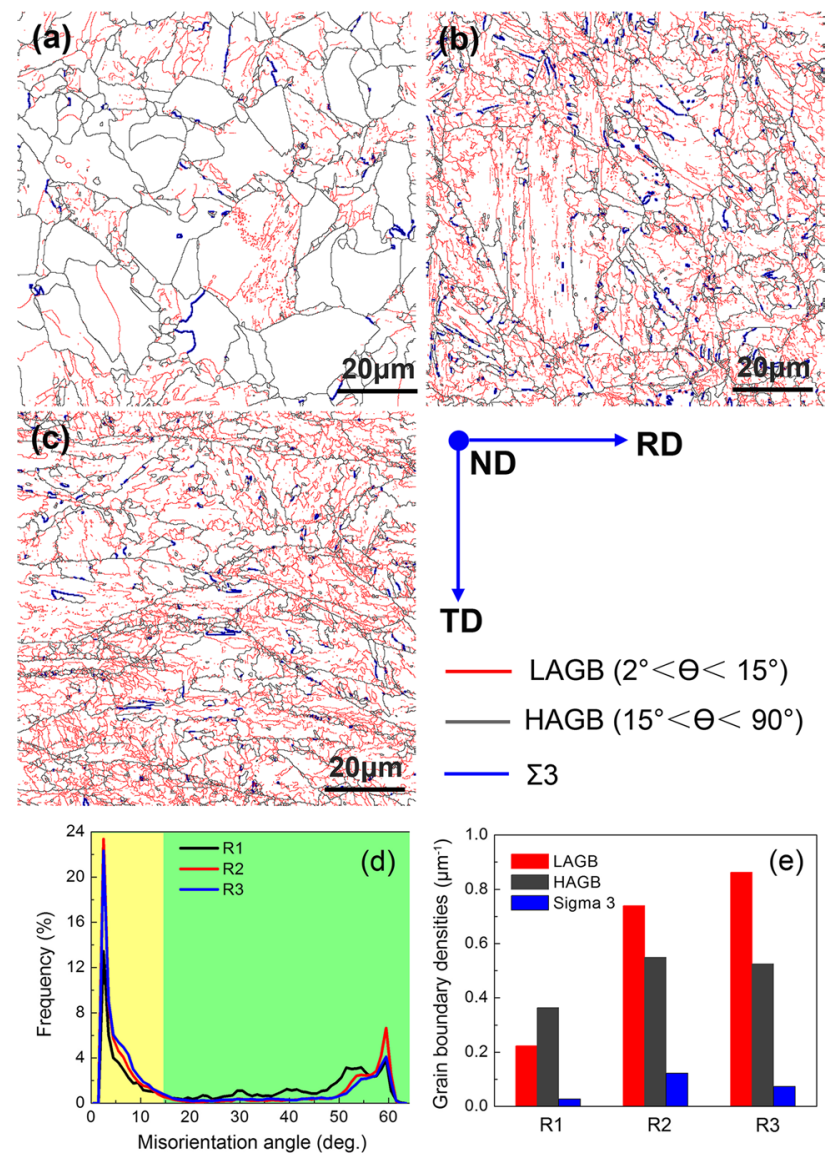

Fig. 6 Grain boundary distribution of R1 a, R2 b, R3 c, grain misorientation distribution $\mathbf{d}$ and measured grain boundary length densities e
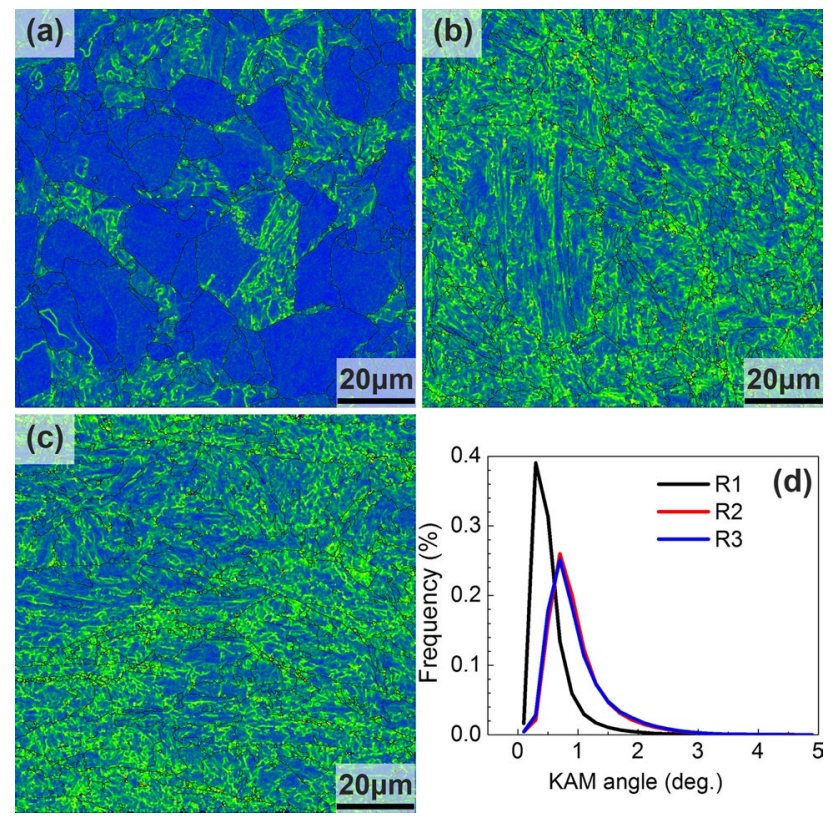

Fig. 7 KAM maps of R1 a, R2 b, R3 c, distribution d within R2 and R3 is probably because of larger rolling reduction and lower FRT, which introduced higher strain and more phase transformation nuclei.

\subsection{Mechanical Properties}

The stress-strain curves of three samples in air and atmosphere were obtained through SSRT tests. The curves closest to the average value in each condition are presented in Fig. 8. The proof yield strength (YS, corresponds to $0.2 \%$ plastic deformation) and ultimate tensile strength (UTS), as well as ductility, were calculated and shown in Fig. 9. It shows $\mathrm{R} 3$ has an excellent mechanical property. Its YS reaches up to $726 \mathrm{MPa}$ with an average elongation of $12.9 \%$. Both the strength and ductility of R3 are substantially higher than that of R1 and R2. In another word, the strength of R3 was improved without sacrifice of ductility. Specifically, the YS and UTS of R3 are equivalent to R2, and considerably higher than that of R1, probably because of grain refinement, dislocation strengthening and lath martensite hardening effect according to the above results (Figs. 4, 5) and the previous literature [57-61]. Although the YS and UTS of R2 are close to that of R3, its elongation is considerably lower than that of R3 probably due to the presence of massive M/A constituents in R2. Extensive studies have demonstrated that massive $\mathrm{M} / \mathrm{A}$ constituents in steel are prone to trigger crack initiation due to local stress concentration between M/A and matrix and are detrimental to ductility and toughness [62-68]. However, M/A constituents are not always harmful and sometimes they could be favorable for mechanical properties, if they are fine in size and are homogeneously distributed [69-71]. Zhao et al. [69] revealed that the bainitic ferrite together with finely distributed M/A constituents provided excellent combination of strength, toughness and crack

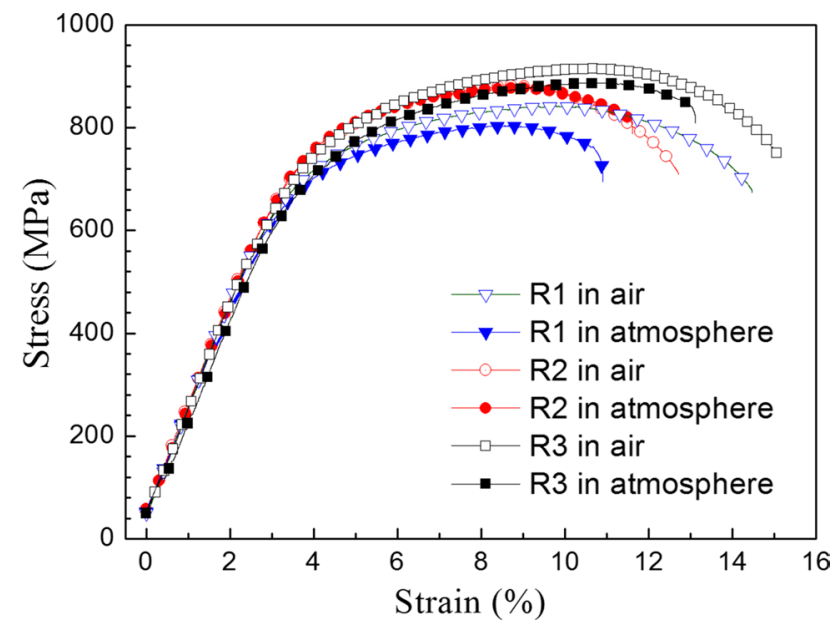

Fig. 8 Stress-strain curves of three samples in air and simulated marine atmosphere 

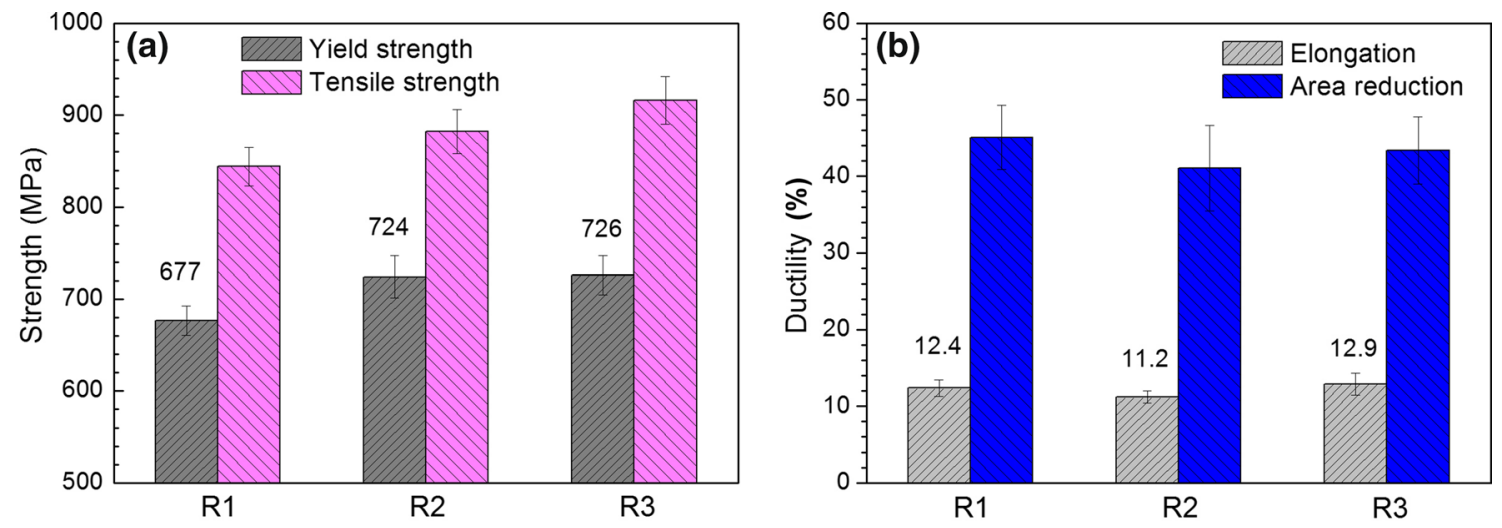

Fig. 9 Yield and tensile strength $\mathbf{a}$ and ductility $\mathbf{b}$ of three samples

arrest property. In brief, R3 has an optimal combination of strength and ductility probably because of dispersive M/A constituents, grain refinement and dislocation strengthening effect, which benefited from multipass rolling within $T_{\mathrm{nr}}$

\subsection{SCC Susceptibility Evaluation}

The representative stress-strain curves of each sample in air and atmosphere are shown in Fig. 8. Both the elongation and mechanical strength of each sample exhibit a considerable decrease in simulated marine atmosphere compared with that in air, thus indicating the occurrence of SCC in this environment. The SCC susceptibility of various samples is evaluated by the loss percentage of elongation $\left(I_{\delta}\right)$ and area reduction $\left(I_{\Psi}\right)$, as shown in Fig. 10. It reveals that all three samples have a high SCC susceptibility in this environment, especially R1 which exhibited an $I_{\delta}$ value of $\sim 30 \%$ and $I_{\Psi}$ of $\sim 50 \%$. The largest loss percentage of ductility of R1 indicates the highest SCC susceptibility, i.e., the lowest SCC resistance. The $I_{\Psi}$ value of R2 is also considerably high, indicating high SCC susceptibility. The relatively lower $I_{\delta}$ value is probably due to its lower original elongation. In contrast, R3 presents the most superior SCC resistance among them probably because of its fine grain size, dispersive M/A constituents and high density of various grain boundaries.

It has been widely demonstrated that LAGBs and $\Sigma 3$ boundaries are immune to microcracks initiation and are beneficial for SCC behavior [48-51]. Although HAGBs may serve as potential crack initiation sites [72-74], they are prevailingly considered as effective barriers to crack propagation and are beneficial for cracking resistance by arresting or deflecting the cracks [75-79]. It should be noted that secondary microcracks on lateral surface were not revealed to initiate from HAGBs in this work. It implies that the beneficial effect of HAGBs on SCC resistance was predominant. Combined with the grain boundary characters in Fig. 6e, the grain boundary densities of R3, irrespective of HAGBs or LAGBs,

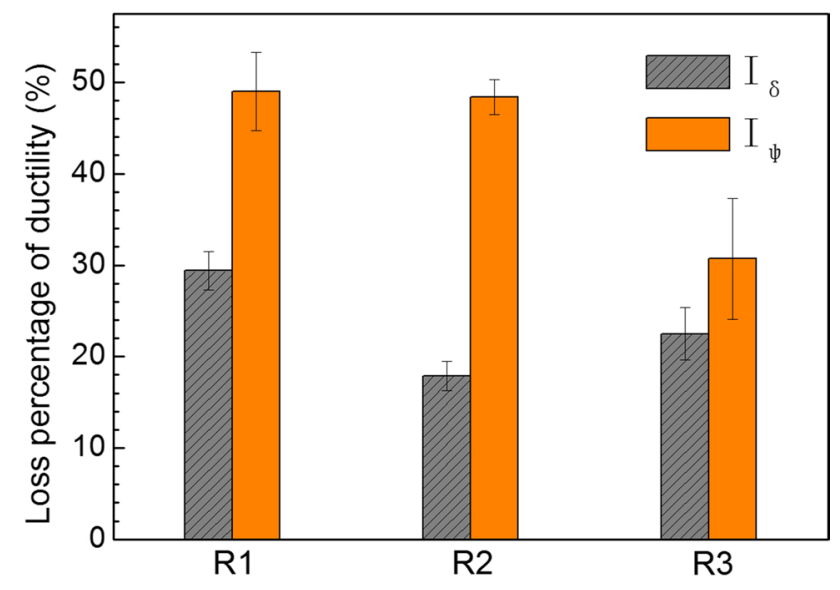

Fig. 10 Loss percentage of ductility of various samples in simulated marine atmosphere compared with that in air

are much higher than those of R1. Therefore, the superior $\mathrm{SCC}$ resistance of R3 can be reasonably ascribed to the fine grain size and high density of various grain boundaries.

\subsection{Fracture Morphologies Observation}

The fracture surface morphologies of these three samples in air and simulated marine atmosphere are presented in Fig. 11. All the fractures in air exhibit ductile failure with obvious necking and numerous dimples on fracture surface, indicating a good ductility for all these three samples, especially R1 and R3, which is consistent with Fig. 9. In addition, the dimples of R3 are more homogeneous probably because of fine and dispersive M/A constituents. Generally, the fine $\mathrm{M} / \mathrm{A}$ constituents as well as other precipitates or inclusions result in the formation of dimples through microvoid mechanism [80, 81]. In contrast, the fractures in atmosphere are relatively flat and smooth without obvious necking. The microscopic images show there are few shallow dimples, 

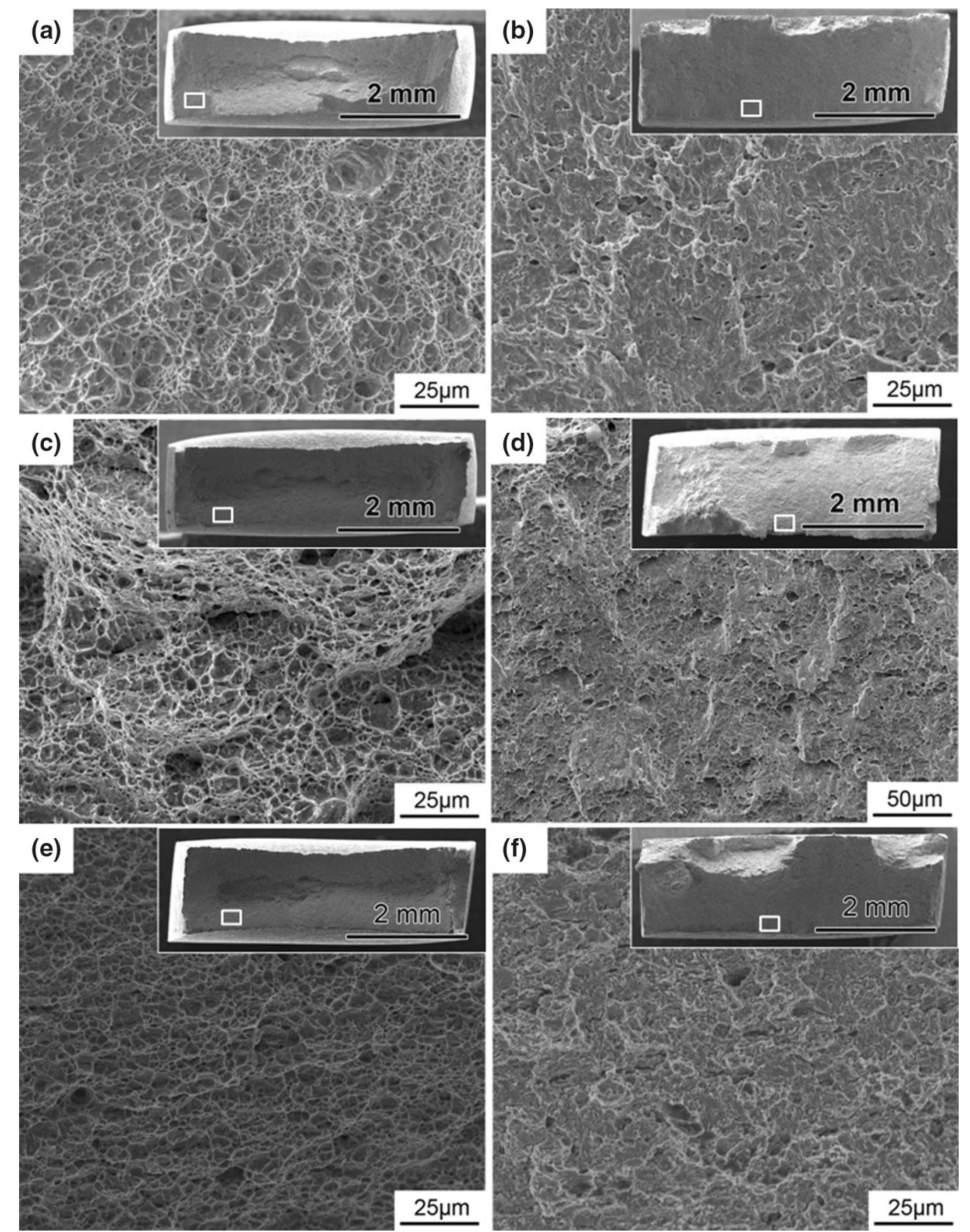

Fig. 11 Surface morphologies of the fractures of R1 a, b, R2 c, d, R3 e, f in air and simulated marine atmosphere. a, c, e Fracture images in air and $\mathbf{b}, \mathbf{d}, \mathbf{f}$ corresponding ones in atmosphere

together with some quasi-cleavage facets on fracture surface. All these features reveal brittle fracture, i.e., the occurrence of SCC in this environment.

The fracture lateral morphologies of these three samples in air and simulated marine atmosphere are presented in Fig. 12. There are no microcracks on fracture surface in air except for the R2 (Fig. 12c). Only some slip bands can be observed due to dislocation slipping and pileup.
The microcracks on fracture surface of $\mathrm{R} 2$ indicate its relatively poor ductility or toughness, which is consistent with the mechanical test results (Fig. 8). However, a lot of secondary microcracks can be observed near the fracture in atmosphere. Specifically, the secondary microcracks of R1 are considerably larger and longer than R2 and R3, whereas those of R2 are deep and very sharp. The longer secondary cracks of $\mathrm{R} 1$ are probably attributed to the less effective 

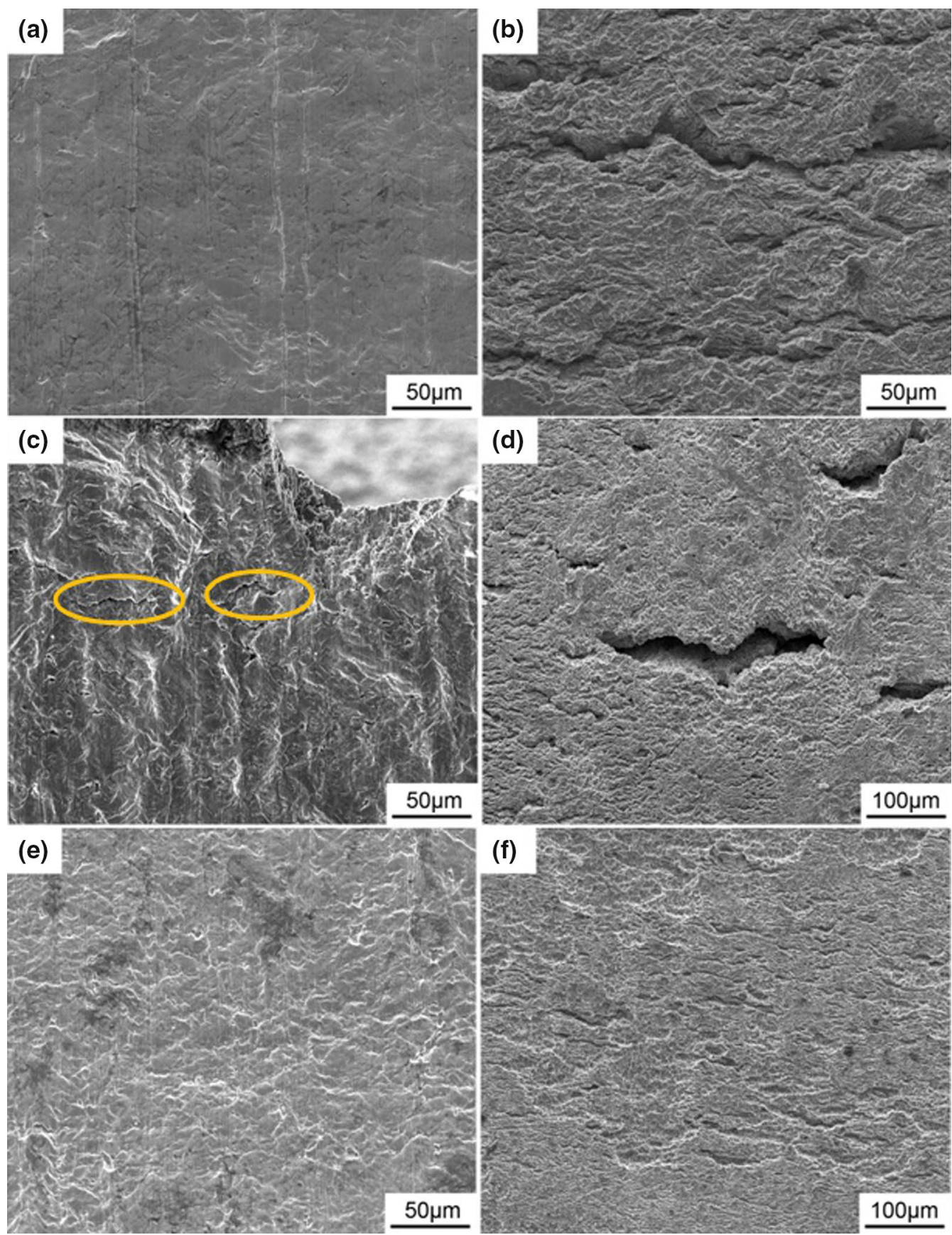

Fig. 12 Lateral morphologies of the fractures of R1 a, b, R2 c, d, R3 e, f in air and simulated marine atmosphere. a, c, e Images in air and b, d, f corresponding ones in atmosphere

crack propagation resistance from HAGBs, and the microcracks were easier to coalesce into longer cracks. The sharp microcracks of R2 may be associated with the massive M/A constituents and its poor ductility. In contrast, the secondary microcracks of R3 are substantially more shallow and blunt, implying a lower SCC sensitivity. These images are consistent with the tendency of SCC susceptibility implied in Fig. 10.
To further investigate the crack propagation image and mechanism, cross-sectional morphologies of the fractures of R1-R3 were observed with SEM after fine polishing and etching (Fig. 13). It shows the secondary cracks of R1 and $\mathrm{R} 2$ are large and sharp, while those of R3 are relatively shallow with typical length of $\sim 10 \mu \mathrm{m}$. In addition, the secondary cracks are mostly transgranular and tend to initiate or propagate along M/A constituents and matrix. According to 
our previous work, this phenomenon is mainly associated with the stress concentration and micro-galvanic corrosion effect between M/A constituents and matrix [34, 72].

\subsection{SCC Mechanism}

According to our previous work, a compact rust layer can be formed during the corrosion in this environment and the rust layer might be ruptured during the dynamic loading $[36,82]$. Then, corrosive ions $\left(\mathrm{Cl}^{-}, \mathrm{H}^{+}\right.$, etc. $)$could reach the substrate surface through the microcracks and induce localized corrosion or corrosion pits underneath the rust layer [83]. Meanwhile, with the hydrolysis reaction of $\mathrm{Fe}^{2+}$ and $\mathrm{H}^{+} / \mathrm{Cl}^{-}$concentration in the bottom of corrosion pits, the localized anodic dissolution and hydrogen evolution would be simultaneously enhanced in the occluded area [84-86]. As a result, microcracks could be induced under the synergistic effect of stress concentration, localized corrosion and hydrogen embrittlemet effect as illustrated in Fig. 14.

If massive M/A constituents were coincidently present on specimen surface or in the bottom of corrosion pits, the initiation of microcracks may be greatly accelerated. Firstly, the M/A constituents could generate local stress concentration under applied stress due to deformation incompatibility with the matrix [71, 82]. Many literature works have demonstrated that massive M/A constituents were prone to trigger crack initiation because of local stress concentration [63-68]. Meanwhile, the massive M/A constituents could result in micro-galvanic corrosion between M/A constituents and matrix due to Volta potential variation $[34,87]$. The Volta potential of M/A constituents was measured to be much higher than that of ferrite matrix and was revealed to be able to induce corrosion pits and initiation of SCC cracks [34]. In addition, M/A constituents are generally considered to be strong hydrogen trapping sites and are supposed to capture much hydrogen around them in this acidic marine environment [88-91]. In this case, the bonding force of M/A constituents with matrix would be further weakened by hydrogen-enhanced decohesion mechanism [91, 92]. Therefore, the initiation of microcracks may be greatly accelerated under the combined effect of local stress concentration, micro-galvanic corrosion and hydrogen embrittlement.

Given that the local stress concentration is associated with the size, morphology and distribution of M/A constituents
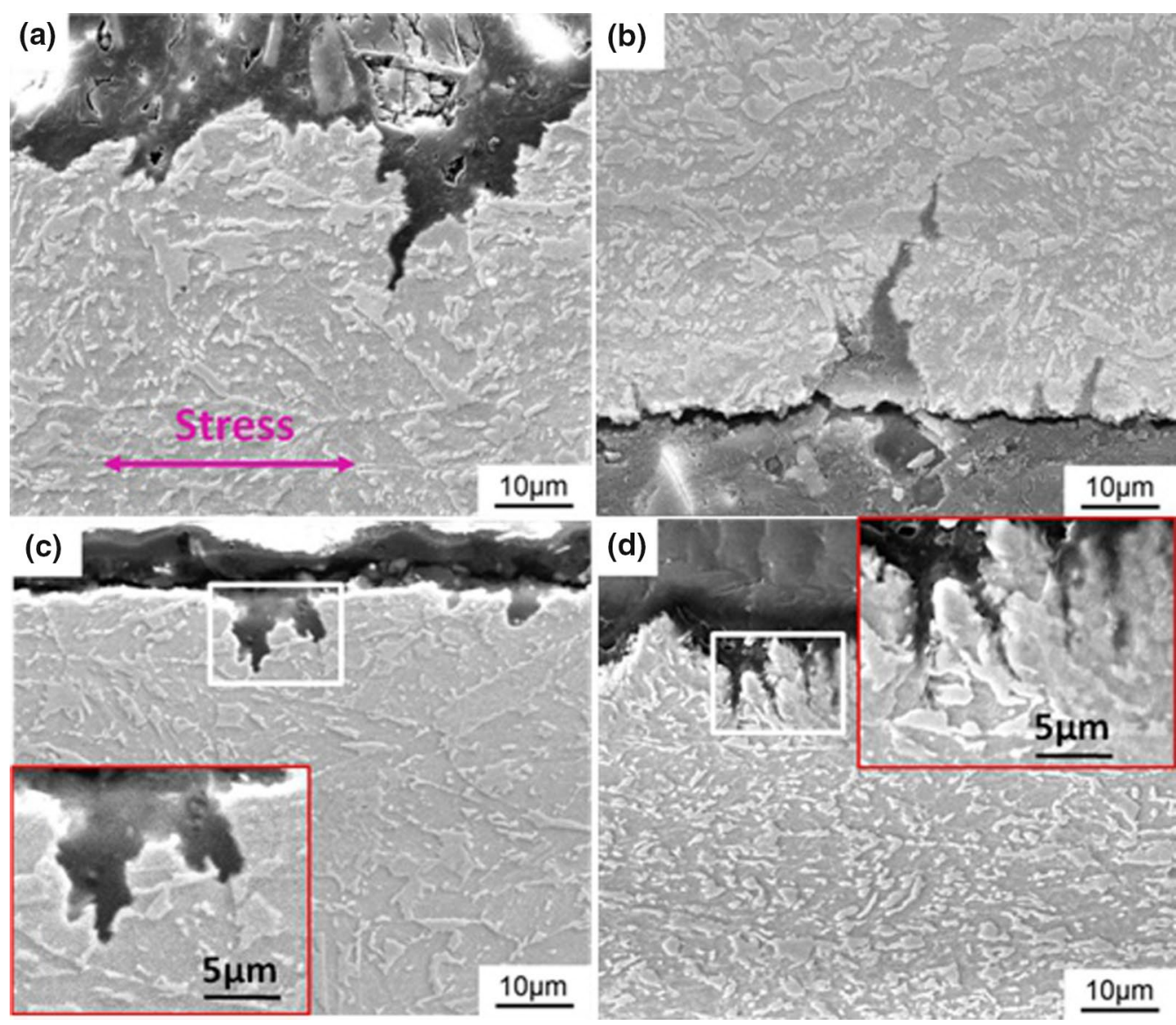

Fig. 13 Cross-sectional morphologies of the fractures of R1 a, R2 b and R3 c, d in simulated marine atmosphere. The images in red boxes are magnified ones in white boxes 

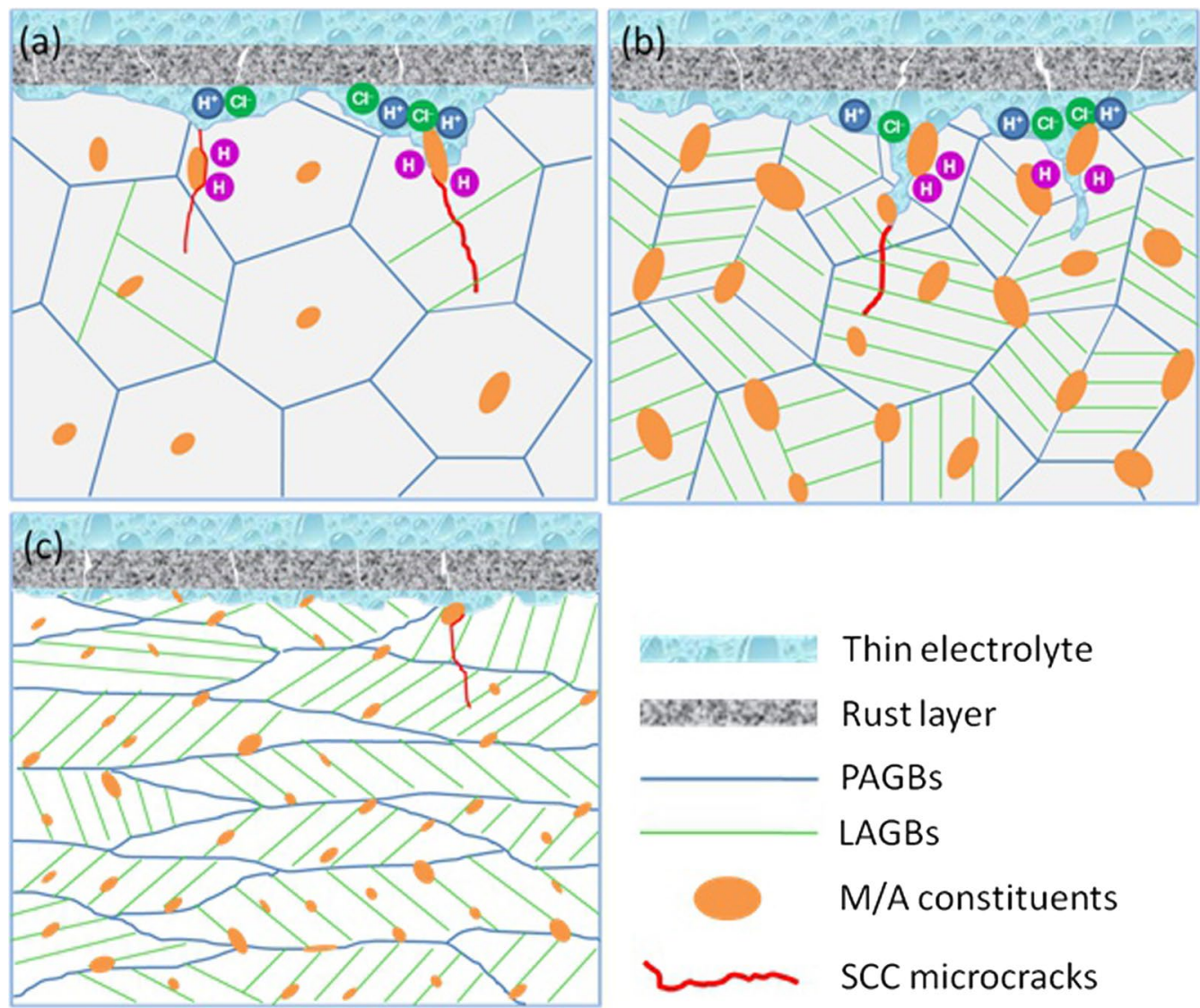

Fig. 14 Schematic of microstructural features and SCC initiation mechanism of R1 a, R2 b, R3 c

[65, 67, 93], larger size of M/A constituents with sharp corner would cause higher local stress concentration $[62,66,67$, 94]. Moreover, the micro-galvanic corrosion effect of larger M/A consistent could be more prominent due to their larger cathode area based on the galvanic corrosion theory [87, 95]. As a result, the massive $\mathrm{M} / \mathrm{A}$ constituents in $\mathrm{R} 2$ were much easier to induce microcracks initiation as depicted in Fig. 14b. Therefore, the poor ductility and high SCC susceptibility of R2 are probably due to the presence of massive $\mathrm{M} / \mathrm{A}$ constituents.

In contrast, as the M/A constituents in R3 are finer and more dispersive, the internal stress in the matrix was more uniform and the local stress concentration around the M/A constituents was mitigated. In addition, the micro-galvanic corrosion effect between them was relatively mild and limited due to smaller size of cathodic phases. Thus, the initiation of SCC could be greatly delayed. On the other hand, even if some microcracks were initiated, the crack propagation would be significantly inhibited by the high density of various grain boundaries as depicted in Fig. 14c. As revealed by Fig. 6, the grain boundary densities of R3 are notably higher than those of R1. The dense grain boundaries, especially HAGBs, can reserve as effective barriers to crack propagation during the SCC process [75-79]. Therefore, the lower SCC sensitivity of R3 relative to R1 and R2 is probably benefited from the fine and dispersive $\mathrm{M} / \mathrm{A}$ constituents, as well as a high density of grain boundary network.

\section{Conclusions}

Based on the above results and analysis, it reveals that the rolling reduction and FRT have a prominent effect on microstructure evolution and mechanical properties, as well as SCC resistance of HSLA steels.

Granular bainite with equiaxed grains was obtained with the FRT within $T_{\mathrm{r}}$, and the grain size was greatly affected by the total rolling reduction. A larger rolling reduction resulted in a considerable decrease in effective grain size and much more grain boundaries, especially $\Sigma 3$ and LAGBs. However, due to the large deformation stored energy and high FRT, the long-range diffusion and partitioning of carbon during phase transformation resulted in the formation of massive $\mathrm{M} / \mathrm{A}$ constituents, which in return caused the low ductility and high SCC susceptibility. 
In contrast, a good combination of strength, ductility and SCC resistance can be simultaneously obtained via multipass rolling within $T_{\mathrm{nr}}$, in which case the effective grain size and $\mathrm{M} / \mathrm{A}$ constituents were greatly refined and were beneficial for the improvement of mechanical properties and SCC behavior.

Acknowledgements This work was financially supported by the National Key Research and Development Program of China (No. 2016YFB0300604), the National Nature Science Foundation of China (51801011), the National Materials Corrosion and Protection Data Center, the State Key Laboratory of Metal Material for Marine Equipment and Application (SKLMEA-K201908) and the Fundamental Research Funds for the Central Universities (FRF-TP-18-026A1).

\section{References}

[1] J. Chen, S. Tang, Z.Y. Liu, G.D. Wang, Mater. Sci. Eng. A 559, 241 (2016)

[2] Y. Zhou, T. Jia, X. Zhang, Z. Liu, R.D.K. Misra, J. Mater. Process. Technol. 219, 314 (2015)

[3] A. Far, S. Anijdan, S.M. Abbasi, Mater. Sci. Eng. A 746, 384 (2019)

[4] O. Berdnikova, V. Pozniakov, A. Bernatskyi, T. Alekseienko, V. Sydorets, Procedia Struct. Integr. 16, 89 (2019)

[5] Y.H. Gao, S.Z. Liu, X.B. Hu, Q.Q. Ren, Y. Li, V.P. Dravid, C.X. Wang, Mater. Sci. Eng. A 759, 298 (2019)

[6] X.G. Li, D.W. Zhang, Z.Y. Liu, Nature 527, 441 (2015)

[7] J. Zhao, Z. Jiang, Prog. Mater. Sci. 94, 174 (2018)

[8] C. Ledermueller, H.I. Pratiwi, R.F. Webster, M. Eizadjou, S.P. Ringer, S. Primig, Mater. Des. 185, 1 (2020)

[9] M. Jahazi, B. Egbali, J. Mater. Process. Technol. 103, 276 (2000)

[10] H.Y. Song, H.T. Liu, H.H. Lu, H.Z. Li, W.Q. Liu, X.M. Zhang, G.D. Wang, Mater. Sci. Eng. A 605, 260 (2014)

[11] G. Cai, C. Li, B. Cai, Q. Wang, Mater. Lett. 238, 249 (2019)

[12] R. Ueji, N. Tsuji, Y. Minamino, Y. Koizumi, Sci. Technol. Adv. Mater. 5, 153 (2004)

[13] L. Bracke, W. Xu, T. Waterschoot, Mater. Today Proc. 2, 659 (2015)

[14] H. Wang, Y. Chen, Procedia Eng. 207, 1839 (2017)

[15] Z.L. Mi, H.T. Jiang, Z.C. Li, M.F. Chen, Z.G. Wang, J. Iron Steel Res. Int. 20, 75 (2013)

[16] S. Yu, L.X. Du, J. Hu, R.D.K. Misra, Mater. Sci. Eng. A 731, 149 (2018)

[17] L.J. Park, J. Tundermann, J. Debarbadillo, Scr. Mater. 37, 1995 (1997)

[18] W.C. Jeong, Mater. Lett. 62, 91 (2008)

[19] H.K. Sung, S.S. Sohn, S.Y. Shin, S. Lee, N.J. Kim, S.H. Chon, J.Y. Yoo, Mater. Sci. Eng. A 541, 181 (2012)

[20] J. Chen, F.T. Dong, H.L. Jiang, Z.Y. Liu, G.D. Wang, Mater. Sci. Eng. A 724, 330 (2018)

[21] A. Saastamoinen, A. Kaijalainen, D. Porter, P. Suikkanen, J.R. Yang, Y.T. Tsai, Mater. Charact. 139, 1 (2018)

[22] A. Kaijalainen, N. Vähäkuopus, M. Somani, S. Mehtonen, D. Porter, J. Kömi, Arch. Metall. Mater. 62, 619 (2017)

[23] B. Hu, X. Tu, H. Luo, X. Mao, J. Mater. Sci. Technol. 47, 131 (2020)

[24] J.I. Omale, E.G. Ohaeri, J.A. Szpunar, M. Arafin, F. Fateh, Mater. Charact. 147, 453 (2019)

[25] E. Ohaeri, J. Omale, U. Eduok, J. Szpunar, Metall. Mater. Trans. A 49, 2269 (2018)
[26] W. Kuang, G.S. Was, C. Miller, M. Kaufman, T. Alam, B. Gwalani, R. Banerjee, Corros. Sci. 130, 126 (2018)

[27] F. Cao, Z. Shi, G.L. Song, M. Liu, M.S. Dargusch, A. Atrens, Corros. Sci. 98, 6 (2015)

[28] Q. Xiang, B. Jiang, Y. Zhang, X. Chen, J. Song, J. Xu, L. Fang, F. Pan, Corros. Sci. 119, 14 (2017)

[29] K. Yamanaka, M. Mori, I. Kartika, M.S. Anwar, K. Kuramoto, S. Sato, A. Chiba, Corros. Sci. 148, 178 (2019)

[30] D. Wang, Z. Ma, Z. Gao, Mater. Chem. Phys. 117, 228 (2009)

[31] A. Otaaghvar, J. Iron Steel Res. Int. 18, 585 (2011)

[32] J. Gautam, A. Miroux, J. Moerman, C. Barbatti, Mater. Sci. Forum 706, 2722 (2012)

[33] H.C. Ma, Y. Fan, Z.Y. Liu, C.W. Du, X.G. Li, Ocean Eng. 182, 188 (2019)

[34] H. Ma, Z. Liu, C. Du, H. Wang, X. Li, D. Zhang, Z. Cui, Corros. Sci. 100, 627 (2015)

[35] H. Ma, C. Du, Z. Liu, W. Hao, L. Chao, Acta Metall. Sin. 52, 331 (2016)

[36] H. Ma, C. Du, Z. Liu, X. Li, Ocean Eng. 164, 256 (2018)

[37] W. Wu, Z. Liu, X. Li, C. Du, Z. Cui, Mater. Sci. Eng. A 759, 124 (2019)

[38] H. Ma, J. Zhao, Y. Fan, Y. Huang, Z. Liu, C. Du, X. Li, Int. J. Fatigue 137, 1 (2020)

[39] L. Lv, L. Fu, S. Ahmad, A. Shan, Mater. Sci. Eng. A 704, 469 (2017)

[40] H. Zheng, L. Fu, Z. Li, X. Ji, Q. Wang, W. Wang, A. Shan, Mater. Today Commun. 21, 1 (2019)

[41] S.C. Wang, J.R. Yang, Mater. Sci. Eng. A 154, 43-49 (1992)

[42] J. Lu, H. Yu, X. Duan, C. Song, Mater. Sci. Eng. A 774, 1 (2020)

[43] M. Gómez, L. Rancel, B.J. Fernández, S.F. Medina, Mater. Sci. Eng. A 501, 188 (2009)

[44] A.M. Ravi, A. Kumar, M. Herbig, J. Sietsma, M.J. Santofimia, Acta Mater. 188, $424(2020)$

[45] X. Li, C. Shang, X. Ma, B. Gault, S.V. Subramanian, J. Sun, R.D.K. Misra, Scr. Mater. 139, 67 (2017)

[46] N. Takayama, G. Miyamoto, T. Furuhara, Acta Mater. 145, 154 (2018)

[47] H. Chen, S. Zhang, G. Shi, Y. Gao, Q. Wang, F. Zhang, Mater. Lett. 189, 136 (2017)

[48] Q. Wu, M. Zikry, Mater. Sci. Eng. A 661, 32 (2016)

[49] K. Ram Reddy, E. Nandha Kumar, R. Jeyaraam, G.D. Janaki Ram, V. Subramanya Sarma, Mater. Charact. 142, 115 (2018)

[50] V. Gertsman, S.M. Bruemmer, Acta Mater. 49, 1589 (2001)

[51] Y. Yuan, Y. Jiang, J. Zhou, G. Liu, X. Ren, Mater. Lett. 253, 424 (2019)

[52] S. Zhang, J. Wan, Q. Zhao, J. Liu, F. Huang, Y. Huang, X. Li, Corros. Sci. 164, 1 (2019)

[53] A.J. Schwartz, W.E. King, M. Kumar, Scr. Mater. 54, 963 (2006)

[54] M. Kamaya, Mater. Charact. 66, 56 (2012)

[55] A. Kundu, D.P. Field, Metall. Mater. Trans. A 49, 3274 (2018)

[56] Q. Wang, R. Zhou, Y. Li, B. Geng, Mater. Charact. 159, 1 (2020)

[57] C. Wang, M. Wang, J. Shi, W. Hui, H. Dong, J. Mater. Sci. Technol. 23, 659 (2007)

[58] J. Chakraborty, P. Chattopadhyay, D. Bhattacharjee, I. Manna, Metall. Mater. Trans. A 41, 2871 (2010)

[59] S. Najafi, A. Eivani, M. Samaee, H. Jafarian, J. Zhou, Mater. Charact. 136, 60 (2018)

[60] T. Liu, Z. Cao, H. Wang, G. Wu, J. Jin, W. Cao, Scr. Mater. 178, $285(2020)$

[61] Z.Y. Cui, Z.Y. Liu, L.W. Wang, X.G. Li, C.W. Du, Mater. Sci. Eng. A 677, 259 (2016)

[62] L. Lan, C. Qiu, H. Song, D. Zhao, Mater. Lett. 125, 86 (2014)

[63] S.G. Lee, S.S. Sohn, B. Kim, W.G. Kim, K.K. Um, S. Lee, Mater. Sci. Eng. A 715, 332 (2018)

[64] N. Huda, A.R.H. Midawi, J. Gianetto, R. Lazor, A.P. Gerlich, Mater. Sci. Eng. A 662, 481 (2016) 
[65] X. Luo, X. Chen, T. Wang, S. Pan, Z. Wang, Mater. Sci. Eng. A 710, 192 (2018)

[66] N. Huda, Y. Wang, L. Li, A.P. Gerlich, Mater. Sci. Eng. A 765, 1 (2019)

[67] D.C. Ramachandran, S.D. Kim, J. Moon, C.H. Lee, J.H. Chung, E. Biro, Y.D. Park, Mater. Lett. 278, 1 (2020)

[68] X. Li, X. Ma, S.V. Subramanian, C. Shang, R.D.K. Misra, Mater. Sci. Eng. A 616, 141 (2014)

[69] J. Zhao, W. Hu, X. Wang, J. Kang, G. Yuan, H. Di, R.D.K. Misra, Mater. Sci. Eng. A 666, 214 (2016)

[70] J.M. Zhang, W.H. Sun, H. Sun, J. Iron Steel Res. Int. 17, 63 (2010)

[71] G. Shi, H. Zhao, S. Zhang, Q. Wang, F. Zhang, Mater. Sci. Eng. A 769, 1 (2020)

[72] H. Ma, L. Chen, J. Zhao, Y. Huang, X. Li, Mater. Sci. Eng. A 773, $1(2020)$

[73] Y.J. Jin, H. Lu, C. Yu, J.J. Xu, Mater. Charact. 84, 216 (2013)

[74] H. Tian, J. Xin, Y. Li, X. Wang, Z. Cui, Corros. Sci. 158, 1 (2019)

[75] Y. Qiao, A.S. Argon, Mech. Mater. 35, 313 (2003)

[76] D. Nakanishi, T. Kawabata, S. Aihara, Acta Mater. 144, 768 (2018)

[77] W. Fang, H. Xie, F. Yin, J. Li, D.F. Khan, Q. Fang, Mater. Sci. Eng. A 666, 314 (2016)

[78] W. Wen, P. Cai, A.H.W. Ngan, T. Zhai, Mater. Sci. Eng. A 666, 288 (2016)

[79] D. Terentyev, F. Gao, Mater. Sci. Eng. A 576, 231 (2013)

[80] Y. Zhou, T. Jia, X. Zhang, Z. Liu, R.D.K. Misra, Mater. Sci. Eng. A 626, 352 (2015)

[81] E.G. Astafurova, V.A. Moskvina, G.G. Maier, A.I. Gordienko, A.G. Burlachenko, A.I. Smirnov, V.A. Bataev, N.K. Galchenko, S.V. Astafurov, Mater. Sci. Eng. A 745, 265 (2019)
[82] H. Ma, Z. Liu, C. Du, X. Li, Z. Cui, Mater. Sci. Eng. A 650, 93 (2016)

[83] Q. Lu, L. Wang, J. Xin, H. Tian, X. Wang, Z. Cui, Constr. Build. Mater. 238, 1 (2020)

[84] C. Liu, R.I. Revilla, D. Zhang, Z. Liu, A. Lutz, F. Zhang, T. Zhao, H. Ma, X. Li, H. Terryn, Corros. Sci. 138, 96 (2018)

[85] L. Wang, J. Xin, L. Cheng, K. Zhao, B. Sun, J. Li, X. Wang, Z. Cui, Corros. Sci. 147, 108 (2019)

[86] H. Ma, B. Zhao, Z. Liu, C. Du, B. Shou, Constr. Build. Mater. 243, $1(2020)$

[87] J. Wei, J. Dong, Y. Zhou, X. He, C. Wang, W. Ke, Mater. Charact. 139, 401 (2018)

[88] Z.Y. Liu, W.K. Hao, W. Wu, H. Luo, X.G. Li, Corros. Sci. 148, 388 (2019)

[89] H. Tian, X. Wang, Z. Cui, Q. Lu, L. Wang, L. Lei, Y. Li, D. Zhang, Corros. Sci. 144, 145 (2018)

[90] E. Malitckii, Y. Yagodzinskyy, P. Vilaça, Mater. Sci. Eng. A 760, 68 (2019)

[91] D.H. Shim, T. Lee, J. Lee, H.J. Lee, J.Y. Yoo, C.S. Lee, Mater. Sci. Eng. A 700, 473 (2017)

[92] M. Koyama, C.C. Tasan, E. Akiyama, K. Tsuzaki, D. Raabe, Acta Mater. 70, 174 (2014)

[93] Y. Li, T. Baker, Mater. Sci. Technol. 26, 1029 (2010)

[94] L. Lan, C. Qiu, D. Zhao, X. Gao, L. Du, Mater. Sci. Eng. A 529, $192(2011)$

[95] F. Mansfeld, Corrosion 27, 436 (1971) 